\title{
Photodermatitis provoked by dapsone: a case report
}

\author{
MARY S JOSEPH \\ Christian Hospital, Manorom-17110, Chainat Province, Thailand
}

\section{Accepted for publication 6 November 1986}

Summary A 61-year-old patient with leprosy developed photodermatitis due to dapsone. The diagnosis was confirmed by clinical trial. This case report demonstrates one of the rare and probably unreported side-effects of the most commonly used antileprosy drug, dapsone.

\section{Introduction}

Diamino-diphenyl sulphone (DDS) which was introduced in the treatment of leprosy in the 1940s acts mainly as a bacteriostatic agent. It is a competitive inhibitor of PABA and it interferes with folate metabolism. Its use does not meet with too many side-effects in the field of leprosy and it is still the most widely used antileprosy drug.

Among the various documented adverse effects of dapsone the skin manifestations include generalized rashes, ${ }^{1-7}$ exfoliative dermatitis, ${ }^{8}$ toxic epidermal necrolysis, ${ }^{9}$ erythema multiforme bullosum ${ }^{10}$ and fixed drug eruptions (FDE) in the form of hyperpigmented macules. ${ }^{1,11,12}$ The author came across a case of pustular and acneiform skin eruptions caused by the drug. ${ }^{13}$ Photosensitivity as a side-effect is not found listed among the skin manifestations as this is an extremely rare sideeffect and probably not yet encountered by leprologists.

\section{Case report}

A 61-year-old Thai female patient with a 5-year history of leprosy, and no previous antileprosy treatment, was admitted at the Nonsombun Leprosarium, Khon Kaen, Thailand on 7 September 1984 for treatment of trophic ulcers of feet. The patient had no history of any drug allergy in the past.

Clinically she was a case of diffuse lepromatous leprosy with bilateral trophic ulcers of hands and feet. Both ulnar and lateral popliteal nerves were uniformly thickened, firm and nontender. There was no significant deformity. The initial BI was 4.5 with MI $4 \%$. Her bodyweight was $50 \mathrm{~kg}$. Systems were normal clinically and $\mathrm{Hb}$ was $10 \cdot 0 \mathrm{gm} \%$.

Antileprosy treatment was started on admission with the MDT/WHO regimen for MB cases, the dose of DDS being $50 \mathrm{mg} /$ day.

From 15 October 1984, 5 weeks after starting treatment, the patient had repeated ENL for which a course of prednisolone was given. On 24 November 1984 (11 weeks after starting DDS) 


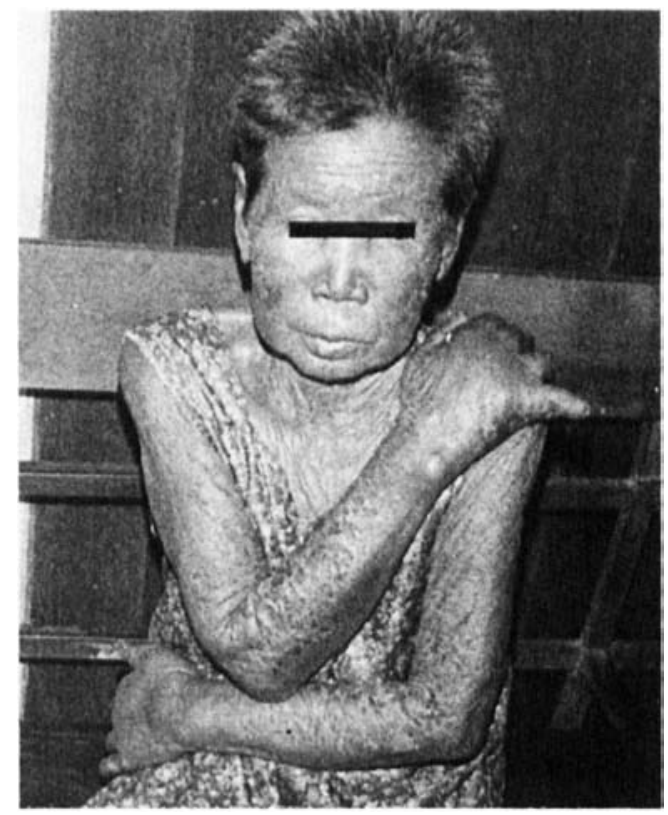

Figure 1. Exfoliation of the skin on the sun-exposed areas and oedema of the face.

while still on prednisolone $5 \mathrm{mg} /$ day for ENL, the patient developed itching, redness and swelling of face. On the next day there was exfoliation of skin over the sun exposed areas, especially of the face and forearms (Figure 1). The covered areas were free of symptoms and signs. In addition the patient had bilateral conjunctivitis. There were no other manifestations such as jaundice, lymphadenopathy, generalized skin eruptions, etc. The patient was febrile, but this could have been due to ENL (because on later occasions when she developed dermatitis on exposure to sunlight there was no fever).

The condition was thought to be a case of photosensitivity induced by dapsone, so the patient was strictly advised to stay indoors to avoid sunlight. A course of prednisolone was restarted for the present condition (ENL was under control by then). Topical skin as well as eye ointments were also prescribed. The dermatitis improved well and by 11 November 1984 prednisolone could be stopped. The patient continued to have slight itching of the involved skin for which only antihistamine (chlorpheniramine maleate) was needed. All antileprosy drugs including DDS were being continued and the patient tolerated them well. She followed the advice and always remained inside the ward. There was no relapse of skin lesions while she remained indoors.

Then, on 15 December 1984, 4 days after being taken off prednisolone and while still on antihistamine, 2 tablets per day, she sat on the verandah exposing herself to the morning sunlight as it was the winter season. But she had to stop after about an hour because she developed itching on the face and neck. The next day there was fresh exfoliation of skin on the sun-exposed areas along with erythema and oedema of face as well as conjunctivitis. Dapsone was stopped on that day, 16 December 1984. Prednisolone was started again along with topical applications and was tapered off over the next few weeks.

Three days after stopping DDS the patient as intentionally exposed to sunlight for an hour at the end of which she had redness and itching over the exposed areas. She was kept indoors again. One week after stopping DDS the patient was able to tolerate the sun and from then on was allowed to move about normally. In fact she was sitting in the morning sunlight along with other patients every day because of the cold winter. The patient continued to do well for over a month. 
In the 6th week after stopping DDS, while the patient was off prednisolone and antihistamine for more than a week, a trial dose of DDS $50 \mathrm{mg}$ was given. There was no adverse effect and DDS was continued for another 2 days. She was kept indoors on the first 2 days while taking DDS and on the 3 rd day was exposed to the sun for 1 hour under close observation. At the end of that 1 hour she had itching and burning on the exposed areas followed by redness. Antihistamine was started immediately but she had mild exfoliation of the skin on the same areas the next day. However, prednisolone was not required this time and there was no conjunctivitis either.

Thus the diagnosis of photosensitivity due to dapsone was confirmed and the drug was stopped altogether. From the beginning of February 1985 the patient had no dapsone. She had already been removed from the WHO regime of MDT since she had to be given high doses of clofazimine for repeated ENL from 6 November 1984, this was gradually reduced later. She was on clofazimine $100 \mathrm{mg} /$ day along with a monthly single dose of rifampicin $(600 \mathrm{mg})$ when the author left that leprosarium on 22 February 1985. There was no dermatitis or ENL at that time, and she was doing very well with normal daily activities involving exposure to the sun.

The author has come across another similar but milder case of dapsone-induced photodermatitis. The patient was a farmer who attended the OP department of the same leprosarium in 1983 . He complained of itching on the face and neck especially after a day's work on the farm. On examination there was redness and mild exfoliation of skin on the above-mentioned areas. There was no oedema or conjunctivitis. Dapsone was stopped temporarily and he was treated as an outpatient with antihistamines and topical lotions. The patient was advised to return after a month for admission to confirm the diagnosis by trial dose, but he did not return. He was a case of tuberculoid leprosy and had dapsone for 3 months before developing the dermatitis.

\section{Discussion}

The patient described in the case report demonstrates a case of photodermatitis provoked by dapsone. The factors favouring the diagnosis are development of dermatitis only on exposure to sunlight while on dapsone, the signs and symptoms being limited to the sun-exposed areas, and a favourable response to stoppage of the offending drug as well as to nonexposure to the sun.

Adverse skin manifestation in the form of dermatitis has been described as part of a hypersensitivity reaction to dapsone $e^{3,4,6,7,12}$ or the so called DADPS syndrome. ${ }^{14}$ But to the author's knowledge, drug-induced photodermatitis has not yet been documented as a side-effect of dapsone. The author has however observed patients with dapsone hypersensitivity who showed an exaggeration of the skin lesions on exposure to the sun, and this was ascribed to the possible phototoxic and photoallergic effects of dapsone. ${ }^{6.13}$

The possibility of a hypersensitivity reaction was ruled out in this patient because the first symptoms appeared after 10 weeks of treatment, whereas hypersensitivity reaction usually manifests within the first 6 weeks of treatment; ${ }^{3,4,6,7}$ the lesions were localized to the sun-exposed areas and appeared only on exposure to the sun while on DDS; the patient could tolerate DDS as long as she remained indoors; and when the trial dose was given the lesions appeared only on the 3rd day when she was exposed to the sun. Other manifestations known to accompany hypersensitivity reaction, namely, fever, lymphadenopathy, generalized skin rash, hepatitis, etc., were also absent.

Photochemical sensitivity reactions can be characterized as photoallergic and phototoxic. ${ }^{15}$ The contact sensitizer may be either exogenous or endogenous. Some of the recognized photocontact sensitizers are halogenated salicylanilides (in soaps and cosmetics), Coumarins, PABA and Benzocaine. ${ }^{16}$ Sulphonamides have photoallergic phototoxic effects. ${ }^{17}$ It is postulated that dapsone acts as an endogenous photosensitizer having eff ects similar to sulphonamides.

The majority of patients with photodermatitis recover when contact with the offending agent is stopped. But some may progress to a condition known as persistent light reaction (PLR), ${ }^{18,19}$ in which case, for reasons unknown the patient continues to develop photosensitivity in the form of 
severe disfiguring dermatitis even when there is no contact with the allergen. Photodermatitis, especially of the PLR type is reported to be caused by halogenated salicylanilides ${ }^{18}$ and bithionol. ${ }^{19}$ But in the case of the patient in the case report, there was no persistent type of sensitivity reaction to light. The patient did have symptoms of itching for up to a week af ter stopping DDS and this could be explained by the fact that detectable blood levels of dapsone remain up to 10 days following a single full dose. It is worth noting that when the trial doses were given after discontinuing the drug for 6 weeks, the symptoms were remarkably mild, whereas when the patient was on DDS for a longer period earlier, the clinical manifestations were more severe, requiring treatment with steroids. This is presumably due to the phototoxic effect of the accumulated amounts of the drug.

\section{Acknowledgment}

The author is extremely thankful to Dr W H Jopling whose guidance and advice have played a large role in the author's work in the field of leprosy and whose suggestions have been of great help in the preparation of this paper. Thanks are also due to the director of Nonsombun Leprosarium for granting permission to publish this paper.

\section{References}

1 Jopling WH. Handbook of Leprosy, 3rd edition. Side effects of Dapsone, p. 87. London: William Heinemann Medical Books Ltd, 1984.

2 Bryceson A, Pfaltzgraff RE. Leprosy, 2nd edition. Side effects of Dapsone, p. 45. New York: Churchill Livingstone, Longman Inc, 1979.

3 Jopling WH. Side effects of antileprosy drugs in common use. Lepr Rev, 1983; 54: 261-70, 1985; 56: 385-9.

4 Tomecki KJ, Catalano CJ. Dapsone Hypersensitivity. Arch Dermatol, 1981; 117: 38-9.

${ }^{5}$ Ramanujam K, Ramu G. Toxic reactions to parent sulfone: report of four cases. Lepr India, 1968; 40(1): 1-7.

6 Joseph Mary S. Hypersensitivity reaction to dapsone: four case reports. Lepr Rev, 1985; 56: 315-20.

7 Kader Naina Mohamed. Hypersensitivity reaction to dapsone: report from Malaysia. Lepr Rev, 1984; 55: 385-9.

${ }^{8}$ Lal S, Garg BR. Sulphone induced exfoliative dermatitis and hepatitis. Lepr India, 1980; 52: 302-5.

9 Katoch K, Ramu G, Ramanathan U. Toxic epidermal necrolysis (Lyell syndrome): a case report. Lepr India, 1983; 55: 133-5.

10 Dutta RK. Erythema multiforme bullosum due to dapsone. Lepr India, 1980; 52: 306-9.

11 Browne SG. A hypermelanotic rash complicating sulphone therapy. Trans $R$ Soc Trop Med Hyg, 1959; 53: 495-505.

12 Ramanujam K. Therapy of Leprosy. In: A Manual of Leprosy, 2nd edition, Thangaraj RH (ed), New Delhi: The Leprosy Mission, 1980, p. 130.

13 Joseph Mary S, Charoen Wisut S. Problems encountered in treating one leprosy patient in a developing country: a case report. Lepr Rev, 1987; 58: 165-171.

14 Allday EJ, Barnes J. Toxic effects of Diamino-Diphenyl sulphone in the treatment of leprosy. Lancet, 1951; 2: 205-6.

is LeVine MJ. Idiopathic photodermatitis with a positive paraphenylenediamine photopatch test. Arch Dermatol, 1984; 120: 1488-90.

${ }^{16}$ Kaidbey KH, Messenger JL. The clinical spectrum of the Persistent Light Reactor. Arch Dermatol, 1984; 120: 1441-8.

17 Pathak MA, Fitzpatrick TB, Parrish JA. In: Harrison's Principles of Internal Medicine, 9th edition. Photosensitivity and other reactions to light, p. 255-62. Isselbacher-Adams-Petersdorf-Wilson. Tokyo: McGraw-Hill Kogakusha Ltd, 1980.

18 Wilkinson DS. Patch test t reactions to certain halogenated salicylanilides. Br J Dermatol, 1962; 74: 302-6.

19 Jillson OF, Baughman RD. Contact photodermatitis from bithionol. Arch Dermatol, 1963; 88: 409-18. 